\title{
Ethanol and protein production from minimally processed biomass of a genetically-modified cyanobacterium over-accumulating sucrose
}

\author{
Maria Eugenia Sanz Smachetti, Macarena Perez Cenci, Graciela L. Salerno, Leonardo Curatti* \\ Instituto de Investigaciones en Biodiversidad y Biotecnología (INBIOTEC-CONICET), Mar del Plata 7600, Argentina \\ Fundación para Investigaciones Biológicas Aplicadas (FIBA), Mar del Plata 7600, Argentina
}

\section{A R T I C L E I N F O}

\section{Keywords:}

Anabaena sp.

Genetic engineering

Sucrose

Biofuels

Bioethanol

\begin{abstract}
A B S T R A C T
One of the main bottlenecks of a microalgal or cyanobacterial biomass biorefinery is the separation of different useful fractions using simple, low energy-consuming, cost-effective, and scalable separation processes. Although the carbohydrates-rich biomass of these microorganisms presents clear advantages over conventional terrestrial crops as feedstocks for ethanol, it still requires acid and/or enzymatic hydrolysis for efficient fermentation. Here, we show the genetic modification of carbohydrates partitioning in a filamentous cyanobacterium towards the accumulation of sucrose up to $10 \%(\mathrm{w} / \mathrm{w})$ as a readily fermentable feedstock. We optimized two methods for the preparation of concentrated sucrose syrups, which were efficiently converted into ethanol by yeasts, without the need of additional pretreatments. Biomass drying and milling, followed by aqueous extraction of sugars and proteins, and the recovery of proteins by short pulses of heat, kept the value of sugars as a feedstock for ethanol and protein for feed supplements within a cost-effective biomass biorefinery.
\end{abstract}

\section{Introduction}

Most techno-economic analysis tends to indicate that costs to produce only biofuels from microalgal or cyanobacterial biomass remain too high for profitable commercialization. Similar analyses also suggest that co-production of biofuels and animal feed, or other higher-value co-products within biomass biorefineries, would largely improve costeffectiveness (Laurens et al., 2017).

In addition to aspects directly related to the cost of producing biomass (Luan and Lu, 2018), the main bottleneck for a biorefinery approach is the separation of different useful fractions using simple, low energy-consuming, cost-effective, and scalable separation processes (Chew et al., 2017; Luan and Lu, 2018).

Microalgal and/or cyanobacterial carbohydrates present considerable advantages over plant-based feedstocks for the production of ethanol (Sanz Smachetti et al., 2018). The lack of lignin and its simpler structure tend to make the pretreatment and saccharification of microalgae or cyanobacterial polysaccharides less energy-intensive and reagent-demanding than current plant-based feedstocks (Sanz Smachetti et al., 2018). It has been shown that microalgal and cyanobacterial carbohydrate-rich biomass can be efficiently hydrolyzed into monosaccharides by chemical (acid or alkaline)/physicochemical or enzymatic hydrolysis (Hernández et al., 2015). While acid hydrolysis, mostly using diluted sulfuric acid, requires high temperatures and produces large volume of contaminating residues, enzymatic hydrolysis can be completed under milder temperatures, although it still requires some physical or chemical pretreatments, and it is considerably more expensive (Hernández et al., 2015). Nevertheless, both strategies lead to biomass saccharification and conversion into ethanol by microbial fermentation with an efficiency very close to the upper theoretical value, as recently compiled by Sanchez Rizza and co-workers (Sanchez Rizza et al., 2017; Sanz Smachetti et al., 2018).

Both microalgae and cyanobacteria can also accumulate soluble sugars, mainly in response to salt, osmotic, desiccation, cold, or heat stress (Kolman et al., 2015; Salerno et al., 2004). In cyanobacteria, the predominant soluble carbohydrates that accumulate upon salt stress are the disaccharides sucrose and trehalose, glucosylglycerol and glucosylglycerate, and sucroglucans (Kolman et al., 2015; Pontis et al., 2007). Sucrose is the most generalized one, and in addition to its function as a compatible solute during environmental stress, it also appears to display other functions in diazotrophic growth and/or in cell signaling pathways in some strains (Cumino et al., 2007; Curatti et al., 2002; Desplats et al., 2005; Kolman et al., 2015). Sucrose metabolism in cyanobacteria is similar to that of microalgae and plants: it is synthesized by the sequential action of sucrose-phosphate synthase (SPS, U/ ADP-glucose: D-fructose-6-phosphate 2- $\alpha$-D-glucosyltransferase, EC 2.4.1.14) and sucrose-phosphate phosphatase (SPP, sucrose-6F-phosphate-phosphohydrolase, EC 3.1.3.24); while its catabolism is initiated

\footnotetext{
* Corresponding author at: Instituto de Investigaciones en Biodiversidad y Biotecnología (INBIOTEC), Vieytes 3103, Mar del Plata 7600, Argentina.

E-mail address: lcuratti@inbiotec.conicet.gov.ar (L. Curatti).
} 
by the activity of three different enzymes: (i) sucrose synthase (SuS, A/ UDP-glucose: D-fructose 2- $\alpha$-D-glucosyltransferase, EC 2.4.1.13); (ii) alkaline/neutral invertase (A/N-Inv, an $\alpha$-glycosidase, EC 3.2.1.261); and (iii) amylosucrase (AMS, EC 2.4.1.4) (Kolman et al., 2015; Salerno and Curatti, 2003).

Soluble carbohydrates such as glucose or sucrose are very attractive carbon sources because they are readily up-taken by yeasts and most microorganism of industrial importance to produce ethanol and other fermentation products without the need of any of the pretreatments already described (Marques et al., 2016; Verstrepen et al., 2004). Thus, during the last years, much attention has been devoted to the genetic modification of unicellular cyanobacteria to increase biosynthesis and release of glucose or sucrose into the medium as an alternative to plant crop-based carbohydrates as fermentation feedstocks (Du et al., 2013; Duan et al., 2016; Ducat et al., 2012; Hays et al., 2017; Kirsch et al., 2018; Löwe et al., 2017; Smith and Francis, 2017; Song et al., 2016; Weiss et al., 2017). Some estimations suggested that sucrose productivity of genetically modified Synechococcus elongatus could be several-fold higher than that of sugarcane, assuming the scalability of laboratory results on either a volumetric or areal basis (Ducat et al., 2012). These sugar-exporting strains cross-fed sugars to heterotrophic microorganisms such as the yeast Saccharomyces cerevisiae or bacteria when co-cultivated (Du et al., 2013; Duan et al., 2016; Ducat et al., 2012; Hays et al., 2017; Löwe et al., 2017; Smith and Francis, 2017; Weiss et al., 2017). In some cases, co-cultures allowed production of target compounds, such as polyhydroxybutyrate, from atmospheric $\mathrm{CO}_{2}$ (Löwe et al., 2017; Smith and Francis, 2017).

In this report we show that a filamentous cyanobacterium overexpressing a sucrose-phosphate synthase encoding-gene over-accumulates sucrose intracellularly up to $10 \%(\mathrm{w} / \mathrm{w})$ of its dry weight after induction by a $\mathrm{NaCl}$ stress. We show optimization of two low energyand reagents-demanding methods for cell collection and preparation of sugar-enriched fractions as suitable feedstocks for ethanol fermentation. Additionally, a large fraction of protein could be recovered as a potential animal feed supplement.

\section{Materials and methods}

\subsection{Plasmid construction and strain transformation}

A mutant strain of Anabaena sp. PCC 7120 was obtained by cloning the native spsB gene (Cumino et al., 2002) in the plasmid pRL1404 in front of its own promoter. The resulting construct was transferred into the cyanobacterium by conjugation. Methods for DNA manipulation and transgenic strains isolation were described before (Curatti et al., 2002).

\subsection{Strains' culture conditions}

Anabaena sp. strain PCC 7120 and the derivative transgenic strain were routinely cultivated in BG11 medium $\left(0.04 \mathrm{~g} \cdot \mathrm{L}^{-1} \quad \mathrm{~K}_{2} \mathrm{HPO}_{4}\right.$; $0.075 \mathrm{~g} \cdot \mathrm{L}^{-1} \mathrm{MgSO}_{4} \cdot 7 \mathrm{H}_{2} \mathrm{O} ; 0.036 \mathrm{~g} \cdot \mathrm{L}^{-1} \mathrm{CaCl}_{2} \cdot 2 \mathrm{H}_{2} \mathrm{O} ; 0.006 \mathrm{~g} \cdot \mathrm{L}^{-1}$ citric acid; $0.006 \mathrm{~g} \cdot \mathrm{L}^{-1}$ ferric ammonium citrate; $0.001 \mathrm{~g} \cdot \mathrm{L}^{-1}$ EDTA (disodium salt); $0.02 \mathrm{~g} \cdot \mathrm{L}^{-1} \mathrm{Na}_{2} \mathrm{CO}_{3}$, and trace metal mix A5 $\left(2.86 \mathrm{mg} \cdot \mathrm{L}^{-1}\right.$ $\mathrm{H}_{3} \mathrm{BO}_{3} ; \quad 1.81 \mathrm{mg} \cdot \mathrm{L}^{-1} \quad \mathrm{MnCl}_{2} \cdot 4 \mathrm{H}_{2} \mathrm{O} ; \quad 0.222 \mathrm{mg} \cdot \mathrm{L}^{-1} \quad \mathrm{ZnSO}_{4} \cdot 7 \mathrm{H}_{2} \mathrm{O}$; $0.39 \mathrm{mg} \cdot \mathrm{L}^{-1} \quad \mathrm{NaMoO}_{4} \cdot 2 \mathrm{H}_{2} \mathrm{O} ; \quad 0.079 \mathrm{mg} \cdot \mathrm{L}^{-1} \quad \mathrm{CuSO}_{4} \cdot 5 \mathrm{H}_{2} \mathrm{O} \quad$ and $\left.0.049 \mathrm{mg} \cdot \mathrm{L}^{-1} \mathrm{Co}\left(\mathrm{NO}_{3}\right)_{2} \cdot 6 \mathrm{H}_{2} \mathrm{O}\right)$ ), containing $1.5 \mathrm{~g} \cdot \mathrm{L}^{-1} \mathrm{NaNO}_{3}$ as a nitrogen source. For isolation and maintenance of the transgenic strain, streptomycin and neomycin were used at $5 \mathrm{mg} \cdot \mathrm{L}^{-1}$ and $150 \mathrm{mg} \cdot \mathrm{L}^{-1}$, respectively.

Strains were maintained in BG11-agar Petri dishes illuminated with constant white light at $6 \mu \mathrm{mol}$ photons $\mathrm{m}^{-2} \cdot \mathrm{s}^{-1}$. For inoculum preparation, strains were first cultivated in $100 \mathrm{~mL}$ Erlenmeyer flasks containing $20 \mathrm{~mL}$ of BG11 medium supplemented with $2.4 \mathrm{~g} \cdot \mathrm{L}^{-1}$ Hepes$\mathrm{NaOH}, \mathrm{pH} 7.5$; with constant agitation at $120 \mathrm{rpm}$ and illuminated with constant white light at $30 \mu \mathrm{mol}$ photons $\mathrm{m}^{-2} \cdot \mathrm{s}^{-1}$. Then, cultures were inoculated into $500 \mathrm{~mL}$ bottles containing $300 \mathrm{~mL}$ of BG11 medium supplemented with $8.4 \mathrm{~g} \cdot \mathrm{L}^{-1} \mathrm{NaHCO}_{3}$ and sparged from the bottom with filtered $\mathrm{CO}_{2}$-enriched air (at about $5000 \mathrm{ppm}$ ) at $0.3-0.5 \mathrm{~L} \cdot \mathrm{min}^{-1}$ and illuminated with constant white light at $75 \mu \mathrm{mol}$ photons $\mathrm{m}^{-2} \cdot \mathrm{s}^{-1}$. Sucrose accumulation experiments were carried out in $5 \mathrm{~L}$ air-lift column photobioreactors (PBRs) containing 4.5 L of BG11 supplemented with $8.4 \mathrm{~g} \cdot \mathrm{L}^{-1} \mathrm{NaHCO}_{3}$, sparged with air from the center of the riser tube at $6 \mathrm{~L} \cdot \mathrm{min}^{-1}$ (up flow circulation) and with pure $\mathrm{CO}_{2}$ from the bottom of the down flow circulation at $0.2 \mathrm{~L} \cdot \mathrm{min}^{-1}$, and illuminated with constant white light at $213.8 \mu \mathrm{mol}$ photons $\mathrm{m}^{-2} \cdot \mathrm{s}^{-1}$. Temperature was maintained constant at $28 \pm 1{ }^{\circ} \mathrm{C}$ in all cases. As indicated in place, cultures were supplemented with $80 \mathrm{mM}$ or $120 \mathrm{mM} \mathrm{NaCl}$.

Cells used to determine SPS activity were cultivated in $250 \mathrm{~mL}$ Erlenmeyer flasks containing $50 \mathrm{~mL}$ of BG11 medium with constant agitation at $120 \mathrm{rpm}$ and illuminated with constant white light at $30 \mu \mathrm{mol}$ photons $\mathrm{m}^{-2} \cdot \mathrm{s}^{-1}$.

For fermentation analysis, the yeast Saccharomyces cerevisiae (Levex ${ }^{\circledR}$, Argentina) was maintained in YPD-agar containing $1 \%$ yeast extract, $2.5 \%$ peptone, $2 \%$ dextrose and $1 \%$ agar-agar, at $28^{\circ} \mathrm{C}$ in the dark.

\subsection{Biomass processing and sugars extraction}

To obtain cyanobacterial sugar-rich extracts, $4.5 \mathrm{~L}$ of Anabaena sp. PCC $7120 w t$ or $s p s B^{+}$cultures were promptly cooled down by adding crashed ice and supplemented with $240 \mathrm{mg} \cdot \mathrm{L}^{-1} \mathrm{FeCl}_{3}$ to promote flocculation. The decanted-cells slurry was further dewatered by centrifugation at $6000 \times g$. For the sugars extraction-method based on microwaves (MW), the cell paste was subjected to extraction by microwaves at $200 \mathrm{~W}$ of power, for 4 cycles of $2 \mathrm{~min}$ each, in a microwave oven (BGH Quick Chef ${ }^{\circledR}$ 15140, Argentina) and the soluble fraction was separated by centrifugation at $17,211 \times g$ for $15 \mathrm{~min}$. The removed volume was replaced with distilled water and centrifuged once again. Both soluble fractions were combined.

For the sugars extraction-method based on dry milling of the biomass (D\&M), the dewatered biomass was air-dried, milled with $15 \%$ sand $(\mathrm{w} / \mathrm{w})$ and rehydrated with water at a 1:3.5 ratio (w/v). Glass beads were added and then, vigorously vortexed. After centrifugation at $11,952 \times g$ for $15 \mathrm{~min}$, the soluble fraction was separated, and the removed volume was replaced with distilled water. This step was repeated 3 times. All soluble fractions were combined and incubated at $100^{\circ} \mathrm{C}$ for $5 \mathrm{~min}$ to partially remove the soluble proteins. Incubation conditions that ensure maximum protein precipitation and minimal sucrose lost were chosen by incubating the extracts at 60 or $100{ }^{\circ} \mathrm{C}$ for $5,10,20$ and $40 \mathrm{~min}$, and protein and sucrose content in the extract was determined (Supplementary Materials). Regardless the method of extraction, soluble fractions were stored at $-20^{\circ} \mathrm{C}$ until further analysis.

\subsection{Fermentation}

Sucrose-rich extracts from Anabaena sp. PCC $7120 w t$ or $s p s B^{+}$ biomass were taken to $\mathrm{pH} 6.5$ with $\mathrm{H}_{2} \mathrm{SO}_{4}$ and supplemented with $19 \mathrm{~g} \cdot \mathrm{L}^{-1} \mathrm{MgSO}_{4}$. Micro-fermentations $(1 \mathrm{~mL})$ were conducted as previously described (Sanchez Rizza et al., 2017) by inoculating the sucrose-rich preparation with $S$. cerevisiae cells at an initial $\mathrm{OD}_{600}$ of 0.25 for 24 or $48 \mathrm{~h}$ at $28^{\circ} \mathrm{C}$ and agitation at $120 \mathrm{rpm}$. Samples were taken periodically, centrifuged at $16,300 \times g$ for $5 \mathrm{~min}$, and supernatants were stored at $-20{ }^{\circ} \mathrm{C}$ until further analysis. As a positive control, fermentation of YPD medium, at a dextrose concentration in the range of sucrose content in the samples, was routinely conducted.

\subsection{Analytical methods}

For dry weight determinations, $50 \mathrm{~mL}$ of resuspended cells in culture medium were first centrifuged at $3900 \times g$ for $10 \mathrm{~min}$, transferred into a $1.5 \mathrm{~mL}$ centrifuge tube and then, centrifuged at $16,300 \times g$ for 

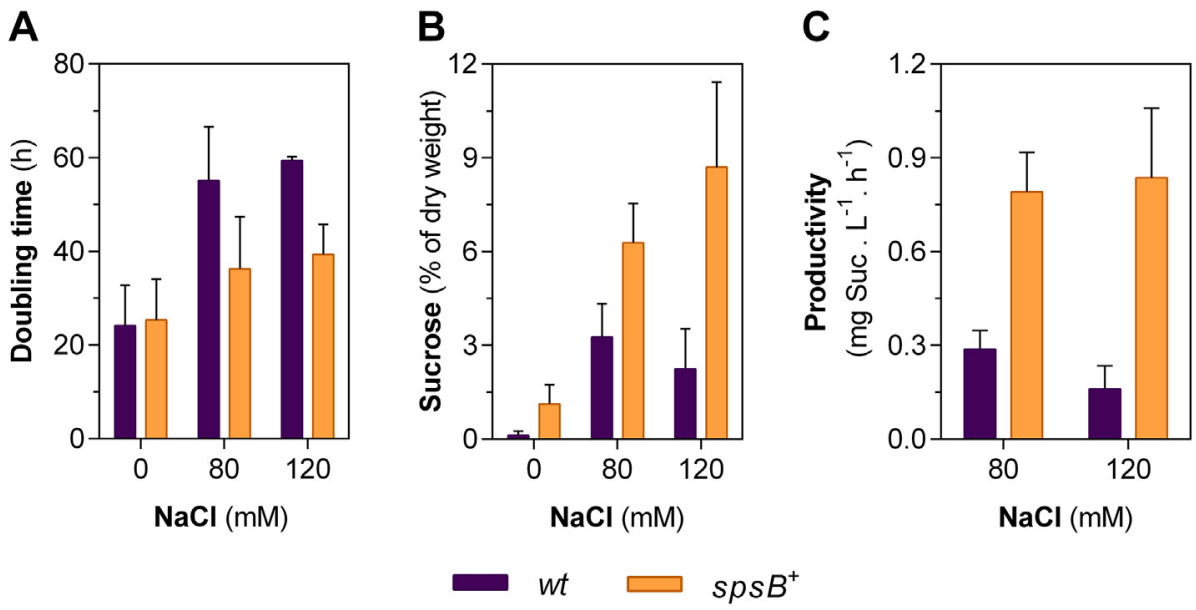

$5 \mathrm{~min}$, at $4{ }^{\circ} \mathrm{C}$. Pellets were dried out in an oven at $90{ }^{\circ} \mathrm{C}$ until constant weight (2-3 days).

For growth curves analysis, cell density was estimated by recording periodically OD at $750 \mathrm{~nm}$ in a UV-1800 spectrophotometer (Shimadzu, Japan). Data were plotted using the GraphPad PRISM software (Intuitive Software for Science, US) and doubling times were obtained by fitting the experimental data to theoretical curves of exponential growth with $\mathrm{R}^{2}$ above 0.96 (Supplementary Materials). Doubling time was also calculated from dry weight data for an observed correspondence below $10 \%$ difference between both methods.

For protein determination, samples of the sucrose-rich extracts were subjected to the Lowry's method (Lowry et al., 1951), using bovine serum albumin as a standard. Alternatively, crude protein was calculated after the combustion of the samples in an atmosphere of ultrapure $\mathrm{O}_{2}$ and helium at $850^{\circ} \mathrm{C}$, total $\mathrm{N}$ was determined in a LECO FP 528 system, using EDTA as a calibration standard, and the standard N-toprotein conversion factor 4.44, characteristic of cyanobacterial protein, was applied (González López et al., 2010).

Total lipids were determined gravimetrically after lipids extraction, basically according to Bligh and Dyer (1959) with modifications (Do Nascimento et al., 2012).

For total carbohydrates determination, samples were reacted with the anthrone reagent (Dreywood, 1946). Standard sucrose extraction and determination were conducted essentially as reported (Pontis, 2017). Briefly, $50 \mathrm{~mL}$ of Anabaena sp. PCC $7120 w t$ or $s p s B^{+}$culture were centrifuged at $3600 \times g$ for $15 \mathrm{~min}$, at $4{ }^{\circ} \mathrm{C}$. Cells were resuspended in 2 volumes of boiling alkaline water $(\mathrm{pH} 8)$, incubated at $100^{\circ} \mathrm{C}$ for $5 \mathrm{~min}$ and then, centrifuged at $9600 \times g$ for $5 \mathrm{~min}$, at $4^{\circ} \mathrm{C}$. Extraction was repeated two more times and the fractions were combined and stored at $-20^{\circ} \mathrm{C}$ until further analysis. For sucrose determination, samples in $100 \mathrm{mM} \mathrm{NaOAc}$, pH 4.5 buffer were incubated at $55^{\circ} \mathrm{C}$ in the presence of $80 \mu \mathrm{g} \cdot \mathrm{mL}^{-1}$ acid invertase (Sigma-Aldridge) for $30 \mathrm{~min}$ for its conversion into glucose and fructose, which were later determined by the Somogyi-Nelson's method with a standard curve using sucrose (Pontis, 2017).

For ethanol determination, yeast spent medium after fermentation was subjected to a method previously reported (Sanchez Rizza et al., 2017). Briefly, the standard ethanol assays contained $50 \mathrm{mM}$ Tris- $\mathrm{HCl}$, $\mathrm{pH} 8.4 ; 2.5 \mathrm{mM} \mathrm{NAD}^{+}$and $3 \mu \mathrm{g}$ protein preparations containing alcohol dehydrogenase activity and the samples in a total volume of $100 \mu \mathrm{L}$ and were incubated at $30^{\circ} \mathrm{C}$ for $25 \mathrm{~min}$. Ethanol was determined as the ethanol-dependent reduction of $\mathrm{NAD}^{+}$at $340 \mathrm{~nm}$ and compared with a standard curve made with $99 \%$ (v/v) analytical grade ethanol.

SPS activity was assayed essentially as reported before (Porchia and Salerno, 1996). Protein extracts were prepared from cells collected from $50 \mathrm{~mL}$ of culture. Cells were resuspended in 3 volumes $(\mathrm{fw} / \mathrm{v})$ of a buffer containing $100 \mathrm{mM}$ Hepes- $\mathrm{NaOH}, \mathrm{pH} 7.5$; $50 \mu \mathrm{M}$ PMSF; $2 \mathrm{mM}$
Fig. 1. Effect of $s p s B$ gene overexpression on growth and sucrose accumulation. A) Cyanobacterial strains doubling time in the presence of different concentrations of $\mathrm{NaCl}$. Data at 0 and $80 \mathrm{mM} \mathrm{NaCl}$ represent the mean and SD of five to eight independent experiments; and at $120 \mathrm{mM}$, the mean and SD of two independent experiments. B) Sucrose content, as percentage of dry biomass, of cells cultured in the presence of different concentrations of $\mathrm{NaCl}$. Data at 0 and $80 \mathrm{mM} \mathrm{NaCl}$ represent the mean and SD of four to ten independent experiments; and at $120 \mathrm{mM}$, the mean and SD of two to four independent experiments. C) Sucrose productivity of Anabaena sp. strains cultured at different concentrations of $\mathrm{NaCl}$. Data at $80 \mathrm{mM} \mathrm{NaCl}$ represent the mean and SD of five or six independent experiments; and at $120 \mathrm{mM}$, the mean and SD of two to four independent experiments.
EDTA; $20 \mathrm{mM} \mathrm{MgCl}_{2} ; 2 \%$ (v/v) ethylene glycol; $20 \mathrm{mM}$ 2-mercaptoethanol; and $20 \%$ glycerol, frozen under liquid $\mathrm{N}_{2}$ and milled in a drill in the presence of acid-washed glass dust. After clarification by centrifugation at $9600 \times g$ for $20 \mathrm{~min}$ at $4{ }^{\circ} \mathrm{C}$, protein extracts were desalted through BioGel P10 resin, previously equilibrated in the same buffer. SPS activity assays, containing $100 \mathrm{mM}$ Hepes- $\mathrm{NaOH}, \mathrm{pH} 7.5 ; 10 \mathrm{mM}$ Fru-6-P; $10 \mathrm{mM}$ UDP-Glc; $20 \mathrm{mM} \mathrm{MgCl}_{2} ; 50 \mathrm{mM} \mathrm{NaF}$; and $5 \mathrm{mM}$ arbutin, were incubated at $30^{\circ} \mathrm{C}$. The production of sucrose-6-P was determined by the thiobarbituric acid method, using fructose as a standard (Pontis, 2017).

\section{Results and discussion}

\subsection{Genetic modification of sucrose accumulation in Anabaena sp. PCC 7120}

We constructed an Anabaena strain over-expressing the spsB gene as an alternative platform for producing readily fermentable sugars. Thus, we placed the native Anabaena sp. PCC 7120 spsB gene, encoding a SPS enzyme (Cumino et al., 2002) and its putative promoter, downstream of the constitutive promoter of pDU1 of the shuttle vector pRL1404.

The transgenic strain showed an average increase of SPS activity of 2-fold, from $1 \mathrm{nmol}$ Fru. $\mathrm{mg}$ prot. ${ }^{-1} \cdot \mathrm{min}^{-1}$ to $2 \mathrm{nmol}$ Fru. $\mathrm{mg}$ prot. $^{-1} \cdot \mathrm{min}^{-1}$, when cells were cultivated under standard growth conditions. Under this culture condition, the transgenic strain showed no growth difference when compared to the parental strain, with doubling times of $25.3 \pm 8.7 \mathrm{~h}^{-1}$ and $24.1 \pm 8.6 \mathrm{~h}^{-1}$, respectively. However, the transgenic line was more tolerant to $\mathrm{NaCl}$ loading in the culture medium, especially at $80 \mathrm{mM} \mathrm{NaCl}$, displaying a doubling time of $36.2 \pm 11.1 \mathrm{~h}^{-1}$, in comparison to $55.1 \pm 11.4 \mathrm{~h}^{-1}$ of the wild type strain (Fig. 1A and Supplementary Materials).

As expected, under standard growth conditions, the mutant strain accumulated 10 -fold more sucrose in its biomass than the parental strain. Under saline stress at $80 \mathrm{mM}$ or $120 \mathrm{mM} \mathrm{NaCl}$ for $48 \mathrm{~h}$, sucrose content of the transgenic line was 2- or 4-fold higher than the wild type, reaching values of $6.3 \pm 1.3(\mathrm{w} / \mathrm{w})$ or $8.7 \pm 2.7 \%(\mathrm{w} / \mathrm{w})$ of their dry biomass, respectively (Fig. 1B). However, the overall sucrose productivity was offset by slower growth under more stringent stressing conditions for a similar productivity at around $0.8 \mathrm{mg} \mathrm{Suc.} \mathrm{L}^{-1} \cdot \mathrm{h}^{-1}$ (Fig. 1C).

Fig. 2 shows that biomass of both Anabaena strains presented similar levels of total carbohydrates at about $27 \%$ (w/w) (Fig. 2A). However, while sucrose represented a minor fraction of total carbohydrates of non-stressed cells of both strains, its level increased up to $43.6 \pm 9.7 \%$ (w/w) of total biomass carbohydrates in the transgenic strain (Fig. 2D).

Thus, $\mathrm{NaCl}$ stress appears to exert a major shift in carbohydrates partitioning, which can be exacerbated by over-expression of a SPS 
A

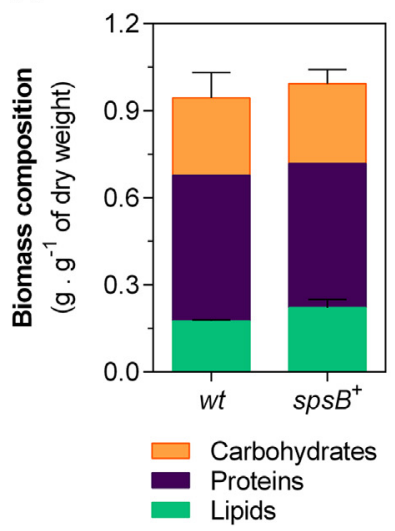

B

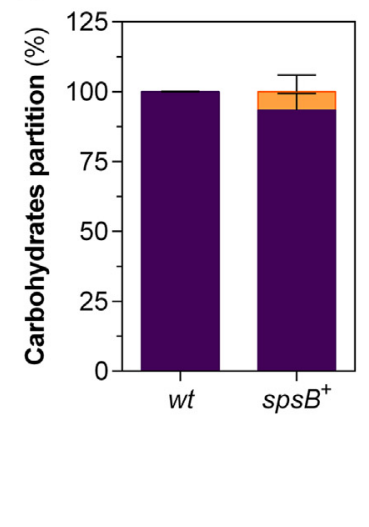

C

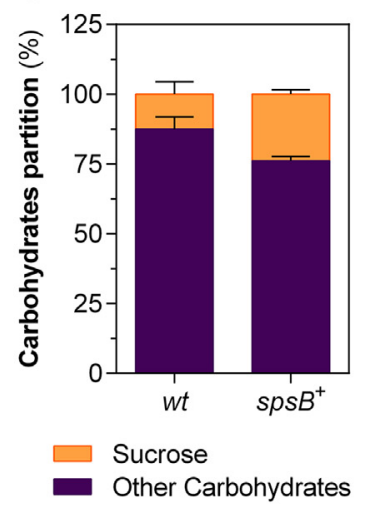

D

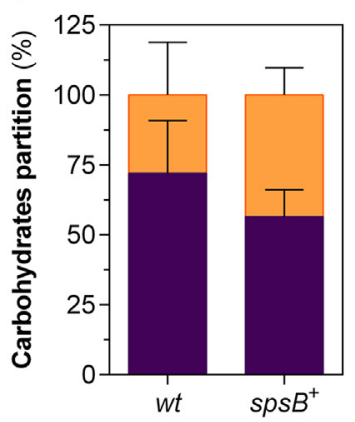

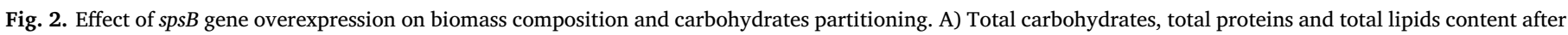

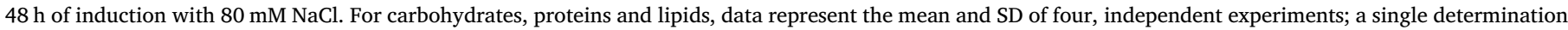

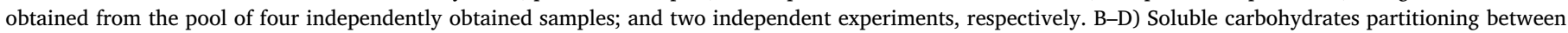

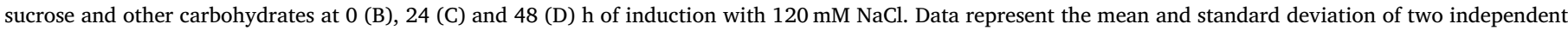
experiments (B and $C$ ) or four independent experiments (D).

encoding-gene. Interconnection between the glycogen and sucrose pools has been demonstrated in some unicellular cyanobacteria, (Ducat et al., 2012; Miao et al., 2003; Qiao et al., 2018; Suzuki et al., 2010; Xu et al., 2013) and also in Anabaena spp. (Curatti et al., 2008). Although it has been generally interpreted that sucrose and glycogen synthesis were competing pathways at the levels of the common substrate glucose-1phosphate, a recent study in S. elongatus PCC 7942 showed that glycogen synthesis was required for $\mathrm{NaCl}$ induction of sucrose accumulation (Qiao et al., 2018). This result suggested that, in addition to mutation of genes for sucrose breakdown (Ducat et al., 2012; Kirsch et al., 2018), metabolic engineering of glycogen synthesis and mobilization could serve as an additional source of glucose-1-phosphate to further boost sucrose accumulation in sps genes over-expressing strains.

It has been pointed out that in order for cyanobacteria to be utilized successfully as biofactories, especially for commodities, tolerance to environmental stress must be increased (Kitchener and Grunden, 2018). Moreover, identifying or creating hyper-tolerant strains either to natural (or even artificially enhanced) stressing conditions, might represent a crop protection strategy by discouraging competitors and/or predators. Sucrose accumulation upon salt stress has long been demonstrated in Anabaena spp. as well as in other cyanobacteria. This has led to the general view that it serves the function of an osmolite enabling cells to stand salt stressing conditions (Kolman et al., 2015; Kirsch et al., 2018). Both sucrose accumulation under osmotic stress and/or high temperatures have led to identical interpretations (Warr et al., 1985). Kitchener and Grunden (2018), discussed the challenge of diverting cellular resources towards an efficient stress tolerance response alongside maximizing accumulation of the target product. The coincidental nature of sucrose as a key player of the stress tolerance response and the target product would represent a very interesting advantage of this platform.

Until this study and regardless of the vast cumulative evidence concerning sucrose accumulation upon salt stress, it has been difficult to accurately estimate up to what extent sucrose accumulation alone could promote salt stress tolerance. Salt stress tolerance is a complex process that, in addition to accumulation of osmolites, also involves active efflux of ions and change in expression of many genes (Hagemann, 2016). Our results suggest the feasibility of increasing tolerance to stress by the same kind of mutations that promote the accumulation of the target product.

\subsection{Sucrose extraction from Anabaena biomass}

Cyanobacterial strains were cultivated in $5 \mathrm{~L}$ photobioreactors and cells were efficiently collected by flocculation in the presence of $\mathrm{FeCl}_{3}$ and further dewatered by mild centrifugation. Then, we optimized two methods for sugar extraction: one consisted in drying and milling (D\& $\mathrm{M})$ the biomass, followed by an aqueous extraction at room temperature (about $22^{\circ} \mathrm{C}$ ) and the other one was based on microwaves (MW) treatment of the wet biomass. Both procedures required further clarification by centrifugation. The D\&M or MW methods allowed recoveries of $54.5 \pm 11.3 \%$ or $84.3 \pm 13.7 \%$ of the sucrose content of the transgenic strain's biomass, respectively. However, the opposite trend was consistently observed for biomass of the $w t$ strain (Fig. 3). Although the reason for this difference is currently not understood, we speculate it can be related to some other pleiotropic effect of the mutation on the structure and/or biochemical composition of the biomass.

The maximum soluble-carbohydrates and sucrose content of the transgenic strain biomass, induced at $120 \mathrm{mM} \mathrm{NaCl}$ and extracted by $\mathrm{D}$ \&M method was $21.5 \pm 0.3 \mathrm{~g} \cdot \mathrm{L}^{-1}$ and $12.9 \pm 1.1 \mathrm{~g} \cdot \mathrm{L}^{-1}$, respectively (Fig. 4).

As a platform for producing fermentable sugars, this alternative strategy brings some advantages over unicellular cyanobacteria overproducing and excreting sucrose. First, larger and filamentous strains, aided by flocculation, are easier to separate from the culture medium. Additionally, sugar retention in the biomass and simplified biomass

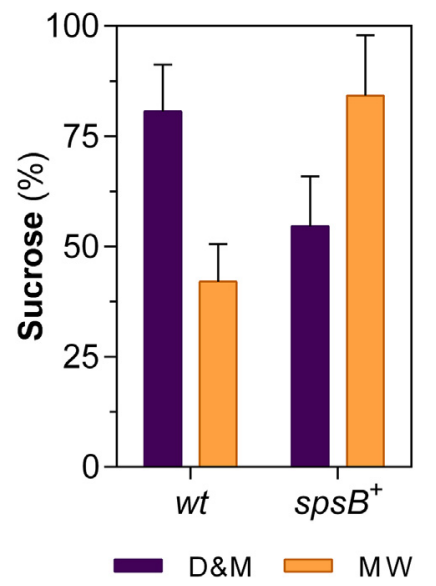

Fig. 3. Biomass sucrose extraction by two alternative methods. D\&M and MW methods. Sucrose extracted by the different methods was expressed as a percentage of total biomass sucrose. Data represent the mean and range of two independent experiments. 
A

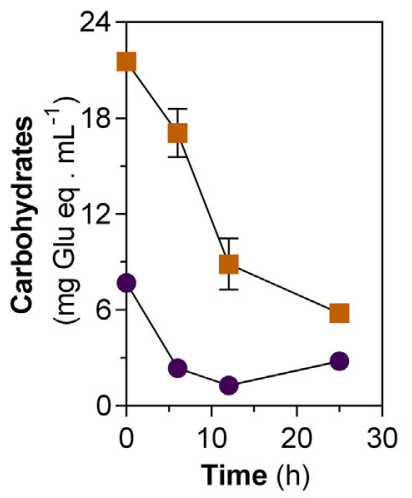

E

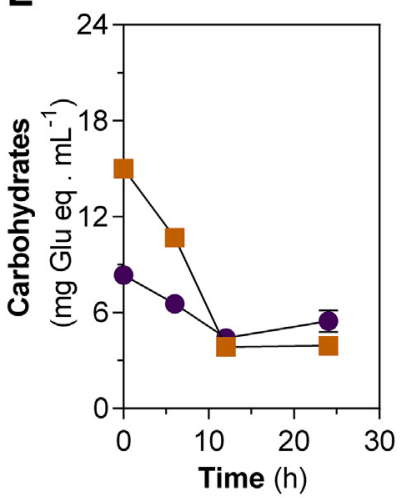

I

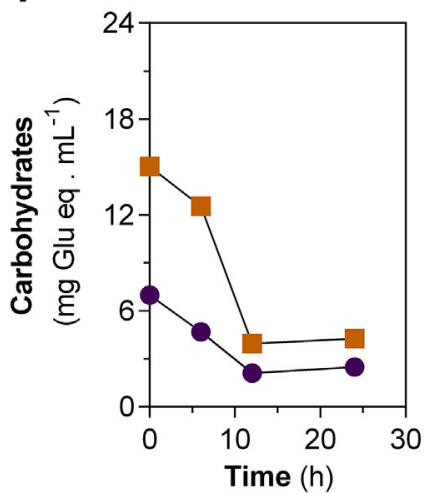

B

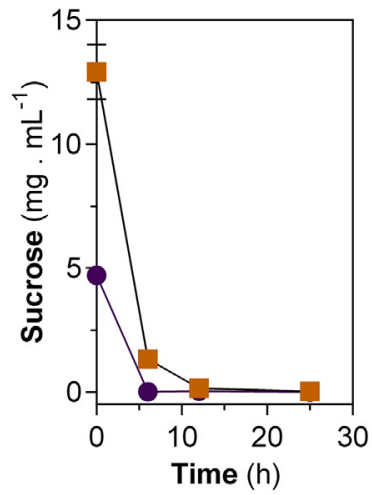

$\mathbf{F}$

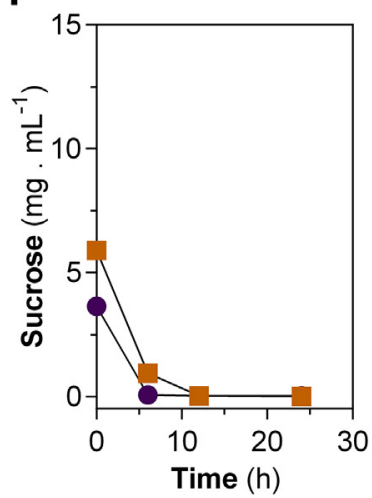

J

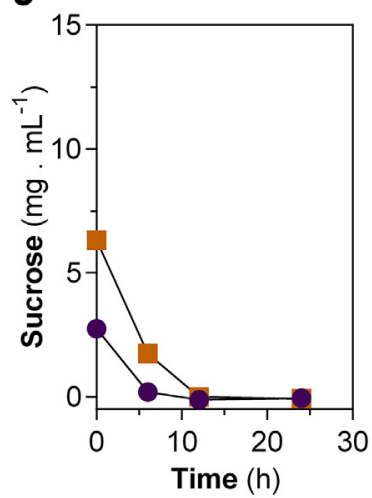

C

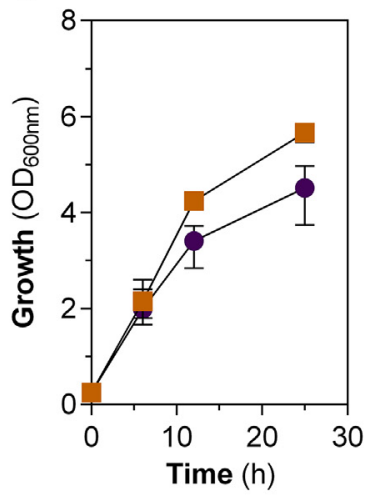

G

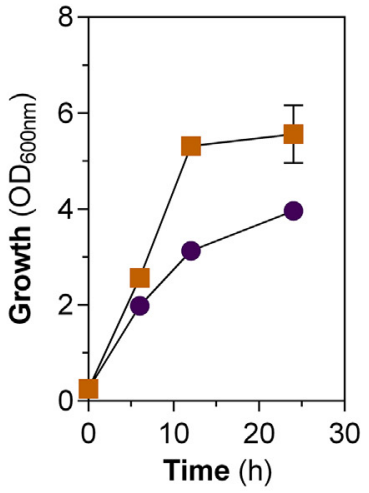

K

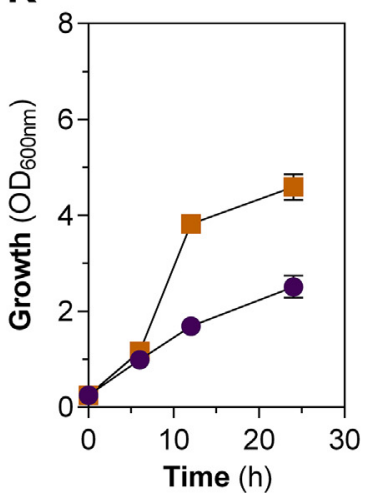

D

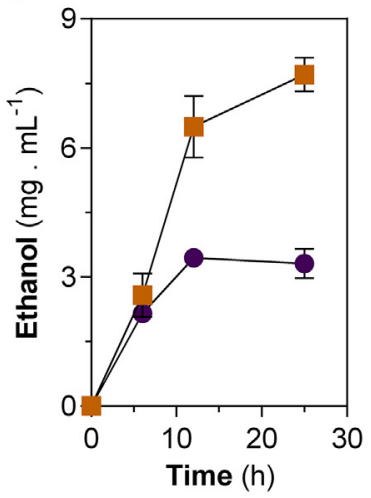

H

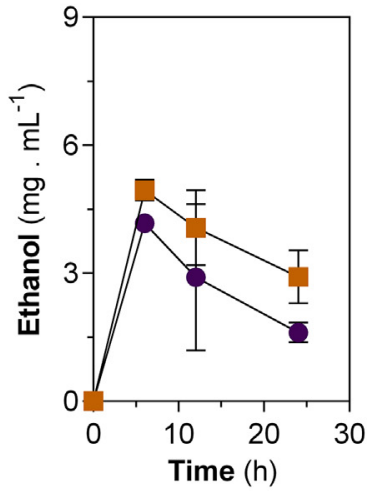

$\mathbf{L}$

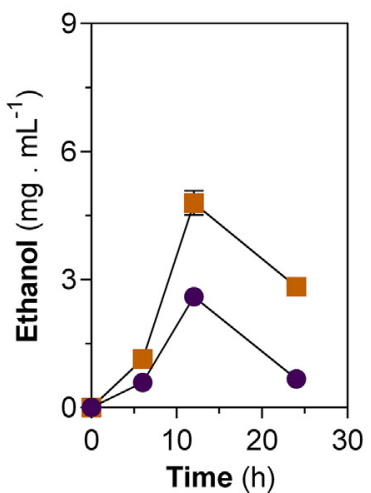

Wt

spsB+

Fig. 4. Time course of the fermentation of the sucrose-rich syrups. Sucrose accumulation was induced at $120 \mathrm{mM}$ (A-D) or $80 \mathrm{mM} \mathrm{NaCl}$ (E-L). Sucrose was extracted from the biomass using the D\&M (A-H) or the MW (I-L) procedures. A, E and I) Depletion of total soluble carbohydrates. B, F and J) Sucrose consumption. C, G and K) Growth curve of $S$. cerevisiae $\left(\mathrm{OD}_{600}\right)$. D, $\mathrm{H}$ and $\mathrm{L}$ ) Ethanol production. The extract obtained via the MW method was supplemented with yeast extract and peptone. The data represent the mean and range of two independent experiments.

recovery allowed us to produce more concentrated preparations of up to $22 \mathrm{~g} \cdot \mathrm{L}^{-1}$ of sugars and up to $13 \mathrm{~g}$ sucrose $\cdot \mathrm{L}^{-1}$. This result improves most frequent concentrations around $1.5 \mathrm{~g}$ sucrose $\mathrm{L}^{-1}$ from sucrose exporting Synecchococcus sp. PCC 7942 strains (Du et al., 2013; Duan et al., 2016; Ducat et al., 2012; Hays et al., 2017; Kirsch et al., 2018; Löwe et al., 2017; Niederholtmeyer et al., 2010; Smith and Francis, 2017; Song et al., 2016; Weiss et al., 2017) and also the most recent improvement after genetic manipulation of sucrose synthesis and export, and cell proliferation at $6 \mathrm{~g}$ sucrose $\mathrm{L}^{-1}$ (Abramson et al., 2018). This aspect may have technological implications if this kind of cyanobacteria-based platforms are to be envisioned as a source of sugars for the production of ethanol, since a minimum of $40 \mathrm{~g}$ ethanol. $\mathrm{L}^{-1}$ would be needed to reduce distillation costs (Möllers et al., 2014). In such a case, and according to the stoichiometry of ethanol fermentation, and assuming a $100 \%$ conversion, this would demand a fermentation broth containing at least $80 \mathrm{~g}$ sugar $\mathrm{L}^{-1}$. A recent study showed the production of up to $72.9 \mathrm{~g}$ sugar $\mathrm{L}^{-1}$ after saccharification of a microalgal biomass with $\mathrm{H}_{2} \mathrm{SO}_{4}$ at high temperature and quantitative conversion into ethanol by $S$. cerevisiae (Sanchez Rizza et al., 2017).

The procedures optimized in this study largely improved the stateof-the-art of the production of concentrated preparations of sugars as fermentation feedstocks without the need of biomass hydrolysis with acids and/or enzymes. However, considerable improvements are still required to bust sugars concentration. These improvements may result 
from a combination of additional genetic modifications and/or host strain selection, and further optimization of biomass processing.

\subsection{Ethanol production from Anabaena sugar preparations}

Ethanol production represents one key example of several alternative fermentation end-products using sugars syrups from cyanobacterial or microalgae. Preliminary attempts of fermenting sugar preparations obtained by the D\&M procedure with $S$. cerevisiae produced low levels of ethanol (data not shown). We observed that this extraction procedure also recovered a large proportion of soluble protein at 23-29 g.L $\mathrm{L}^{-1}$, which increased the viscosity of the extracts (not shown). Thus, we analyzed the effect of temperature on sugar and protein separation and the stability of sucrose. We observed that incubations as short as $5 \mathrm{~min}$ at $100{ }^{\circ} \mathrm{C}$ were enough to recover about $90 \%$ of the proteins as insoluble material while sucrose content remained unchanged (Supplementary Materials).

Deproteinized sugar preparations were quantitatively converted into ethanol by fermentation with $S$. cerevisiae. Fig. 4 shows the time course of total sugars (Fig. 4A, E and I) or sucrose (Fig. 4B, F and J) depletion, the concomitant growth of the yeast (Fig. 4C, G and K), and increase in ethanol production (Fig. 4D, H and L). Sucrose-rich extracts from biomass induced at $120 \mathrm{mM} \mathrm{NaCl}$ and processed according to D\& $\mathrm{M}$ method (Fig. 4A-D) contained total soluble carbohydrates at $7.7 \pm 0.8 \mathrm{~g} \cdot \mathrm{L}^{-1}$ or $21.6 \pm 0.5 \mathrm{~g} \cdot \mathrm{L}^{-1}$ for the $w t$ type or transgenic biomass, respectively. These preparations also contained sucrose at $4.7 \pm 0.4 \mathrm{~g} \cdot \mathrm{L}^{-1}$ or $12.9 \pm 0.5 \mathrm{~g} \cdot \mathrm{L}^{-1}$ for the $w t$ type or transgenic biomass, respectively. Fermentation of these preparations produced ethanol up to $3.4 \pm 0.2 \mathrm{~g} \cdot \mathrm{L}^{-1}$ or $7.7 \pm 0.6 \mathrm{~g} \cdot \mathrm{L}^{-1}$ for the $w t$ type or transgenic biomass, respectively (Fig. 4D). Consumed carbohydrates were converted into ethanol at least up to $89.4 \%$ or $70.2 \%$ of the maximum theoretical value of $0.51 \mathrm{~g}$ ethanol.g glucose ${ }^{-1}$, from the biomass of the $w t$ or the transgenic strain, respectively.

While sucrose was completely consumed by the yeast (Fig. 4B, F and $J$ ), a soluble carbohydrates fraction remained non-metabolized by $S$. cerevisiae under the used fermentation conditions (Fig. 4A, E and I). Although not experimentally demonstrated in this work, it is presumed that the carbohydrates fraction that remained non-metabolized by $S$. cerevisiae could correspond to sucroglucans. These oligosaccharides represent, after sucrose, the second most abundant fraction of the soluble carbohydrates that accumulate in Anabaena and Nostoc strains exposed to salt stress (Salerno et al., 2004). Sucroglucans share the general structure $[\alpha-D-G l c p-(1 \rightarrow 2)]_{n}-\alpha-D-G l c p-(1 \rightarrow 2)-\beta$-D-Fruf, and are characterized by a [ $\alpha$-D-Glcp-(1 $\rightarrow 2)]$ linkage that is quite non frequent in nature (Pontis et al., 2007). Although accumulation in cyanobacteria can be reverted upon reversal of the salt stress (Salerno et al., 2004), the catabolism of sucroglucans is largely unknown, and appeared not to involve [ $\alpha$-D-( $1 \rightarrow 4)]$ glucosidase, invertase or sucrase activities (Pontis et al., 2007). Thus, to further improve this platform for the production of fermentable sugars, the nature of these carbohydrates must be confirmed, and its metabolic pathways elucidated in order to design engineering strategies to further modify the partitioning of carbon in the cyanobacterium and/or to transfer appropriate genes to microorganisms to allow fermentation into products.

Similar results were obtained from cyanobacteria induced with $80 \mathrm{mM} \mathrm{NaCl}$ using the D\&M (Fig. 4E-H) or the MW (Fig. 4I-L) methods, respectively. However, unlike with the D\&M method, sugars prepared by the MW method, required supplementation of an additional source of nutrients such as yeast extract, for a more efficient conversion into ethanol (Figs. 4 and 5, and Supplementary Materials).

When integrating results from sucrose productivity by the cyanobacteria, efficiency of sugars extraction, and conversion into ethanol, it was observed that the transgenic strain produced about twice the ethanol per unit of biomass culture volume, regardless of the biomass processing method (Fig. 5).

Recently, an elegant study showed cell type-specific metabolic engineering of Anabaena sp. PCC 7120 to express Zymomonas mobilis pyruvate decarboxylase and Synechocystis sp. PCC 6803 alcohol dehydrogenase genes exclusively in heterocysts. In contrast to the $\mathrm{O}_{2}$-evolving photosynthetic vegetative cells, heterocysts differentiate from vegetative cells upon combined $\mathrm{N}$ shortage and execute a complex shift in genes expression which down-regulates $\mathrm{O}_{2}$-evolving photosynthesis and induces $\mathrm{N}_{2}$-fixation, which is a strict anaerobic pathway. A mutant strain additionally overexpressing an invertase gene in heterocysts, and assisted by an optimized gas-stripping strategy, accumulated ethanol at $1.7 \mathrm{~g}$ in 23 days. This yield represented a three-fold improvement in comparison to previous similar studies conducted in unicellular cyanobacteria in which, as expected, fermentation appeared to be attenuated by the $\mathrm{O}_{2}$ produced by photosynthesis (Ehira et al., 2018). The platform described in our study produced considerably higher levels of ethanol from Anabaena sp. PCC 7120 cells at about $8 \mathrm{~g}$ in three days (two for biomass production and one for fermentation). Regardless of this progress, it becomes quite evident that achievable yields are still far away in comparison to plant feedstocks (Sanz Smachetti et al., 2018) to envision commercial competitiveness of a platform dedicated to the production of only ethanol. However, ethanol production might be considered if it occurs within a biomass biorefinery for additional products (Laurens et al., 2017), and especially, if it minimizes the use of chemicals and enzymes.

\subsection{Additional cyanobacterial biomass biorefinery for recovery of protein and other cellular fractions}

Both methods allowed the separation of a soluble fraction rich in sugars as a direct feedstock for ethanol. Since in the MW method protein precipitation occurred inside the cells, protein can be recovered along other water insoluble cell materials. Conversely, if extraction proceeded through the D\&M method, about $50 \%$ of the total biomass crude-protein could be isolated in a water-soluble form from either strain (Fig. 6). After mild heating of these preparations, sugars remained soluble and were separated from the insoluble protein fraction (Supplementary Materials). About $20 \%$ of the dry biomass could be recovered in these fractions (Fig. 6).

There is an increasing interest to partially replace conventional sources of protein, such as soybean meal, fish meal, rice bran, etc., by microalgal and/or cyanobacterial protein for animal feeding, especially poultry and in aquaculture (Becker, 2007). Both, nutritional and toxicological determinations supported the suitability of algal biomass as a valuable feed supplement or substitute. Comparative data on biological value, digestibility coefficient, net protein utilization, and protein efficiency ratio of algal proteins suggested a quality slightly lower than those of casein or egg protein (Becker, 2007). However, poor digestibility of whole algal biomass due to the cellulosic cell wall, especially of some microalgae, is frequently one of the major drawbacks towards algal biomass used as feed (Becker, 2007). Thus, efficient (Lupatini et al., 2017; Safi et al., 2014) and especially cost-effective treatments, as those proposed in this study, are necessary to increase the feasibility of algal biomass as a partial replacement of protein- for- feed production. It has been reported that Scenedesmus obliquus biomass drying and cooking improved the digestibility coefficient and net protein utilization (Becker, 2007).

Cyanobacterial biomass is characterized by a low content of lipids (Hu et al., 2008). However, although not demonstrated here, the residual biomass after applying the D\&M method followed by aqueous extraction of carbohydrates and protein would become enriched in lipids, which could be further biorefined for feed supplements and/or a biodiesel feedstock, as needed.

\section{Conclusion}

This study shows the genetic modification of carbohydrates partitioning in a filamentous cyanobacteria towards accumulation of sucrose 
A

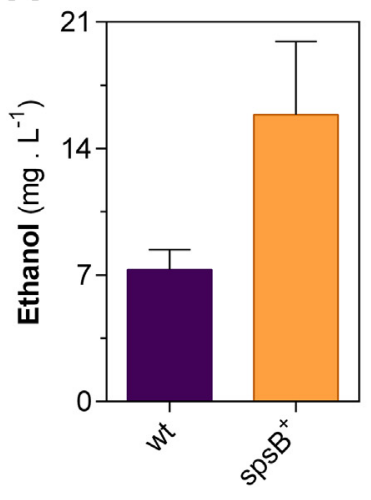

B

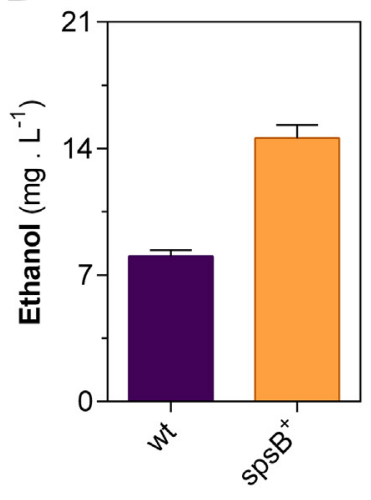

C

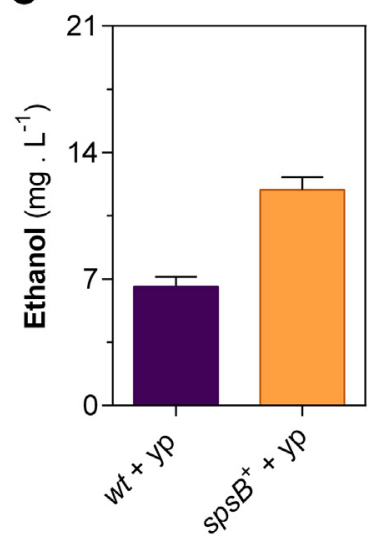

Fig. 5. Effect of $s p s B$ gene overexpression on biomass and sucrose production and conversion into ethanol. A-C) Ethanol production on a culture volumetric basis. Sucrose accumulation was induced at $120 \mathrm{mM}$ (A) or $80 \mathrm{mM}$ (B-C) $\mathrm{NaCl}$. Sucrose was extracted according to the D\&M (A-B) or the MW (C) methods. In (C), syrups were supplemented with yeast extract and peptone. The data represent the mean and standard deviation of four (120 mM) or two $(80 \mathrm{mM})$ independent experiments.
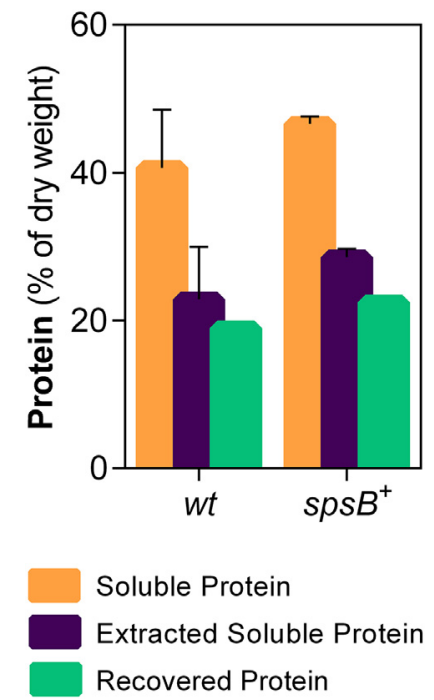

Fig. 6. Protein recovery from of Anabaena sp. PCC 7120 biomass. Total soluble protein in the biomass; extracted soluble protein by the D\&M method; or recovered by heating. For total and extracted soluble protein, data represent the mean and range of two independent experiments and a single determination for heat-insolubilized protein.

as a readily fermentable feedstock. We optimized two methods for costeffective preparation of concentrated sucrose syrups which could be efficiently converted into ethanol by yeasts. The D\&M method followed by aqueous extraction of carbohydrates and protein, and protein recovery by short pulses of heat could keep the value of sugars, protein and lipids for different applications in the food, energy and/or other sectors of the market.

\section{Acknowledgements}

The authors are very grateful to CD Coronel, M Do Nascimento, L Sanchez Rizza and R Ambrosio for helpful discussions and N Almada for technical assistance. MESS is a doctoral fellow and LC is career researchers at CONICET, Argentina. This work was supported by grants PICT2012-2589 and PICT2015-3559 from the Agencia Nacional de Promoción Científica y Tecnológica, Argentina to LC.

\section{Appendix A. Supplementary data}

Supplementary data to this article can be found online at https:// doi.org/10.1016/j.biteb.2019.01.019.

\section{References}

Abramson, B.W., Lensmire, J., Lin, Y.-T., Jennings, E., Ducat, D.C., 2018. Redirecting carbon to bioproduction via a growth arrest switch in a sucrose-secreting cyanobacterium. Algal Res. 33, 248-255.

Becker, E.W., 2007. Micro-algae as a source of protein. Biotechnol. Adv. 25, 207-210.

Bligh, E.G., Dyer, W.J., 1959. A rapid method of total lipid extraction and purification. Can. J. Biochem. Physiol. 37, 911-917.

Chew, K.W., Yap, J.Y., Show, P.L., Suan, N.H., Juan, J.C., Ling, T.C., Lee, D.-J., Chang, J. S., 2017. Microalgae biorefinery: high value products perspectives. Bioresour. Technol. 229, 53-62.

Cumino, A., Curatti, L., Giarrocco, L., Salerno, G.L., 2002. Sucrose metabolism: Anabaena sucrose-phosphate synthase and sucrose-phosphate phosphatase define minimal functional domains shuffled during evolution. FEBS Lett. 517, 19-23.

Cumino, A.C., Marcozzi, C., Barreiro, R., Salerno, G.L., 2007. Carbon cycling in Anabaena sp. PCC 7120. Sucrose synthesis in the heterocysts and possible role in nitrogen fixation. Plant Physiol. 143, 1385-1397.

Curatti, L., Flores, E., Salerno, G., 2002. Sucrose is involved in the diazotrophic metabolism of the heterocyst-forming cyanobacterium Anabaena sp. FEBS Lett. 513, 175-178.

Curatti, L., Giarrocco, L.E., Cumino, A.C., Salerno, G.L., 2008. Sucrose synthase is involved in the conversion of sucrose to polysaccharides in filamentous nitrogen-fixing cyanobacteria. Planta 228, 617-625.

Desplats, P., Folco, E., Salerno, G.L., 2005. Sucrose may play an additional role to that of an osmolyte in Synechocystis sp. PCC 6803 salt-shocked cells. Plant Physiol. Biochem. 43, 133-138.

Do Nascimento, M., Ortiz-Marquez, J.C.F., Sanchez-Rizza, L., Echarte, M.M., Curatti, L., 2012. Bioprospecting for fast growing and biomass characterization of oleaginous microalgae from South-Eastern Buenos Aires, Argentina. Bioresour. Technol. 125, 283-290.

Dreywood, R., 1946. Qualitative test for carbohydrate material. Ind. Eng. Chem. Anal. Ed. $18,499$.

Du, W., Liang, F., Duan, Y., Tan, X., Lu, X., 2013. Exploring the photosynthetic production capacity of sucrose by cyanobacteria. Metab. Eng. 19, 17-25.

Duan, Y., Luo, Q., Liang, F., Lu, X., 2016. Sucrose secreted by the engineered cyanobacterium and its fermentability. J. Ocean Univ. China 15, 890-896.

Ducat, D.C., Avelar-Rivas, J.A., Way, J.C., Silver, P.A., 2012. Rerouting carbon flux to enhance photosynthetic productivity. Appl. Environ. Microbiol. 78, 2660-2668.

Ehira, S., Takeuchi, T., Higo, A., 2018. Spatial separation of photosynthesis and ethanol production by cell type-specific metabolic engineering of filamentous cyanobacteria. Appl. Microbiol. Biotechnol. 102 (3), 1523-1531.

González López, C.V., García, M.d.C.C., Fernández, F.G.A., Bustos, C.S., Chisti, Y., Sevilla, J.M.F., 2010. Protein measurements of microalgal and cyanobacterial biomass. Bioresour. Technol. 101, 7587-7591.

Hagemann, M., 2016. Coping with high and variable salinity: molecular aspects of compatible solute accumulation. In: Borowitzka, M.A., Beardall, J., Raven, J.A. (Eds.), The Physiology of Microalgae. Springer International Publishing, Cham, pp. 359-372.

Hays, S.G., Yan, L.L.W., Silver, P.A., Ducat, D.C., 2017. Synthetic photosynthetic consortia define interactions leading to robustness and photoproduction. J. Biol. Eng. $11,4$.

Hernández, D., Riaño, B., Coca, M., García-González, M.C., 2015. Saccharification of carbohydrates in microalgal biomass by physical, chemical and enzymatic pretreatments as a previous step for bioethanol production. Chem. Eng. J. 262, 939-945.

Hu, Q., Sommerfeld, M., Jarvis, E., Ghirardi, M., Posewitz, M., Seibert, M., Darzins, A., 2008. Microalgal triacylglycerols as feedstocks for biofuel production: perspectives and advances. Plant J. 54, 621-639.

Kirsch, F., Luo, Q., Lu, X., Hagemann, M., 2018. Inactivation of invertase enhances sucrose production in the cyanobacterium Synechocystis sp. PCC 6803. Microbiology 164, 1220-1228.

Kitchener, R.L., Grunden, A.M., 2018. Methods for enhancing cyanobacterial stress tolerance to enable improved production of biofuels and industrially relevant chemicals. 
Appl. Microbiol. Biotechnol. 102 (4), 1617-1628.

Kolman, M., Nishi, C., Perez-Cenci, M., Salerno, G., 2015. Sucrose in cyanobacteria: from a salt-response molecule to play a key role in nitrogen fixation. Life 5, 102-126.

Laurens, L.M.L., Markham, J., Templeton, D.W., Christensen, E.D., Van Wychen, S., Vadelius, E.W., Chen-Glasser, M., Dong, T., Davis, R., Pienkos, P.T., 2017. Development of algae biorefinery concepts for biofuels and bioproducts; a perspective on process-compatible products and their impact on cost-reduction. Energy Environ. Sci. 10, 1716-1738.

Löwe, H., Hobmeier, K., Moos, M., Kremling, A., Pflüger-Grau, K., 2017. Photoautotrophic production of polyhydroxyalkanoates in a synthetic mixed culture of Synechococcus elongatus $\operatorname{cscB}$ and Pseudomonas putida cscAB. Biotechnol. Biofuels 10, 190.

Lowry, O.H., Rosebrough, N.J., Farr, A.L., Randall, R.J., 1951. Protein measurement with the Folin phenol reagent. J. Biol. Chem. 193, 265-275.

Luan, G., Lu, X., 2018. Tailoring cyanobacterial cell factory for improved industrial properties. Biotechnol. Adv. 36, 430-442.

Lupatini, A.L., Colla, L.M., Canan, C., Colla, E., 2017. Potential application of microalga Spirulina platensis as a protein source. J. Sci. Food Agric. 97, 724-732.

Marques, W.L., Raghavendran, V., Stambuk, B.U., Gombert, A.K., 2016. Sucrose and Saccharomyces cerevisiae: a relationship most sweet. FEMS Yeast Res. 16 (fov107 fov107).

Miao, X., Wu, Q., Wu, G., Zhao, N., 2003. Sucrose accumulation in salt-stressed cells of agp gene deletion-mutant in cyanobacterium Synechocystis sp. PCC 6803. FEMS Microbiol. Lett. 218, 71-77.

Möllers, K.B., Cannella, D., Jørgensen, H., Frigaard, N.-U., 2014. Cyanobacterial biomass as carbohydrate and nutrient feedstock for bioethanol production by yeast fermentation. Biotechnol. Biofuels 7, 64.

Niederholtmeyer, H., Wolfstädter, B.T., Savage, D.F., Silver, P.A., Way, J.C., 2010. Engineering cyanobacteria to synthesize and export hydrophilic products. Appl. Environ. Microbiol. 76, 3462-3466.

Pontis, H.G., 2017. Mehods for Analysis of Carbohydrate Metabolism in Photosynthetic Organisms: Plants, Green Algae and Cyanobacteria. Academis Press, Elsevier.

Pontis, H.G., Vargas, W.A., Salerno, G.L., 2007. Structural characterization of the members of a polymer series, compatible solutes in Anabaena cells exposed to salt stress. Plant Sci. 172, 29-35.

Porchia, A.C., Salerno, G.L., 1996. Sucrose biosynthesis in a prokaryotic organism: presence of two sucrose-phosphate synthases in Anabaena with remarkable differences compared with the plantenzymes. Proc. Natl. Acad. Sci. U. S. A. 93, 13600-13604.

Qiao, C., Duan, Y., Zhang, M., Hagemann, M., Luo, Q., Lu, X., 2018. Effects of reduced and enhanced glycogen pools on salt-induced sucrose production in a sucrose-secreting strain of Synechococcus elongatus PCC 7942. Appl. Environ. Microbiol. 84 (e02023-17).

Safi, C., Ursu, A.V., Laroche, C., Zebib, B., Merah, O., Pontalier, P.-Y., Vaca-Garcia, C. 2014. Aqueous extraction of proteins from microalgae: effect of different cell disruption methods. Algal Res. 3, 61-65.

Salerno, G.L., Curatti, L., 2003. Origin of sucrose metabolism in higher plants: when, how and why? Trends Plant Sci. 8, 63-69.

Salerno, G.L., Porchia, A.C., Vargas, W.A., Abdian, P.L., 2004. Fructose-containing oligosaccharides: novel compatible solutes in Anabaena cells exposed to salt stress. Plant Sci. 167, 1003-1008.

Sanchez Rizza, L., Sanz Smachetti, M.E., Do Nascimento, M., Salerno, G.L., Curatti, L., 2017. Bioprospecting for native microalgae as an alternative source of sugars for the production of bioethanol. Algal Res. 22, 140-147.

Sanz Smachetti, M.E., Sanchez Rizza, L., Coronel, C.D., Do Nascimento, M., Curatti, L., 2018. Microalgal biomass as an alternative source of sugars for the production of bioethanol. In: Kuila, A., Sharma, V. (Eds.), Principle and Application of Fermentation Technology. Wiley-Scrivener Publishing LLC, USA, pp. 351-386.

Smith, M.J., Francis, M.B., 2017. Improving metabolite production in microbial co-cultures using a spatially constrained hydrogel. Biotechnol. Bioeng. 114, 1195-1200.

Song, K., Tan, X., Liang, Y., Lu, X., 2016. The potential of Synechococcus elongatus UTEX 2973 for sugar feedstock production. Appl. Microbiol. Biotechnol. 100, 7865-7875.

Suzuki, E., Ohkawa, H., Moriya, K., Matsubara, T., Nagaike, Y., Iwasaki, I., Fujiwara, S. Tsuzuki, M., Nakamura, Y., 2010. Carbohydrate metabolism in mutants of the cyanobacterium Synechococcus elongatus PCC 7942 defective in glycogen synthesis. Appl. Environ. Microbiol. 76, 3153-3159.

Verstrepen, K.J., Iserentant, D., Malcorps, P., Derdelinckx, G., Van Dijck, P., Winderickx, J., Pretorius, I.S., Thevelein, J.M., Delvaux, F.R., 2004. Glucose and sucrose: hazardous fast-food for industrial yeast? Trends Biotechnol. 22, 531-537.

Warr, S.R.C., Reed, R.H., Stewart, W.D.P., 1985. Carbohydrate accumulation in osmotically stressed cyanobacteria (blue-green algae): interactions of temperature and salinity. New Phytol. 100, 285-292.

Weiss, T.L., Young, E.J., Ducat, D.C., 2017. A synthetic, light-driven consortium of cyanobacteria and heterotrophic bacteria enables stable polyhydroxybutyrate production. Metab. Eng. 44, 236-245.

Xu, Y., Tiago Guerra, L., Li, Z., Ludwig, M., Charles Dismukes, G., Bryant, D.A., 2013. Altered carbohydrate metabolism in glycogen synthase mutants of Synechococcus sp. strain PCC 7002: cell factories for soluble sugars. Metab. Eng. 16, 56-67. 